\title{
IV. בllatizen.
}

\section{Jum Bleffingfhen Sḩraubenleil.}

Der Erfinber biejes $\mathfrak{B e r f z e n g e s , ~ f u ̈ r ~ m e l d e s ~ f e i t ~ e i n i g e r ~ B e i t ~ v i e l ~ \Re e l l n m e ~ g e m a d t ~}$

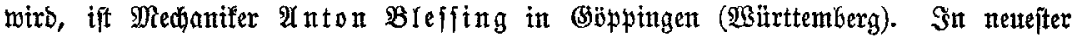
3eit wirb ber Sajraubenfeil von den Sägenfabrifanten $\Im$. D. Domintcus \& Sährte

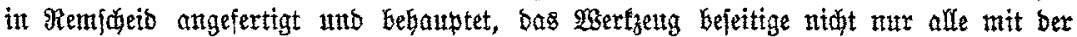

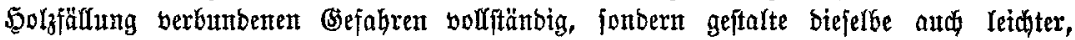
idheller unb wentger anftrengend. Man propbezeite bem Shraubenfeil, wie bas ja oft bei neiten Erfinbungen vortommt, eine grope 3 ufumft.

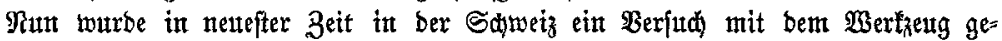
madit, ${ }^{1}$ ) welder feinesinegs fehr gïnftig ausfiel. Derferbe hat forgenber ergeken:

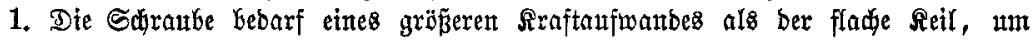
gleide Birfunts zu exzielen.

2. Das $\mathfrak{A}$ ifekent ift fofmitertger unb zeitraubetto.

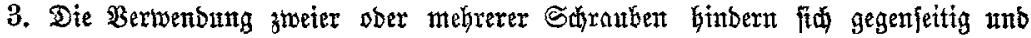
bies fonn aud fïr bie beftimmung ber Fallridutung berGängnigboll merben.

4. Die Sarauben find tener and nidit jo leidft zal reparieren.

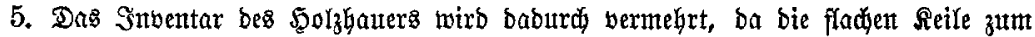
Spalten bez Sdizetholzzez bod nidit entbeḩrt werben lüntten.

Da ms aud fdon von anberer Seite etwas abfällige ltrteiYe za Shren famen,

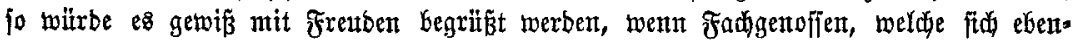
falls mit bem (Begenftanbe bejdjättigt Gaben, in biejen 8 lättern ibre gemadjen Erfahrungen gïtigft mitteifent wollten. ${ }^{2}$ )

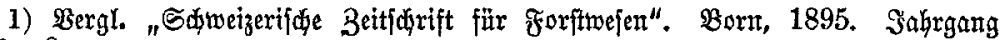
$46, \mathfrak{N r} .2$.

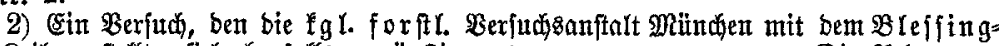
fajen Reile anftellte, fiel ebenfalfs untg̈̈ntig ans. Die Reb.

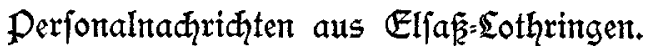

\section{Duartal 1895.}

Drbensyerleibungen: Dberforftmeifter פartleben= Solmar, Roter Irblerorben 3 Rl. mit Sdileife; Forftmeifter Saroeber= Saargemïno, Rronenorben 3. Rl. (bei

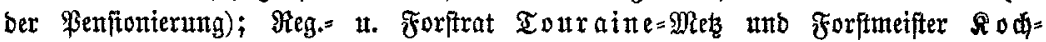
Dberehnkeim, Roter Isterorben 4. RI.

Benfoniert: Forftmeifter Squoeber = Saargemünb vom 1. Ipril ab.

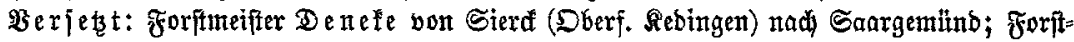

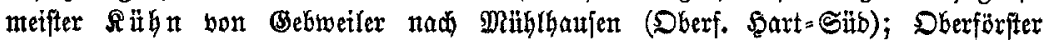
Sortoring bon Rübelftein nach Gebroiler.

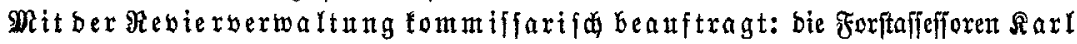

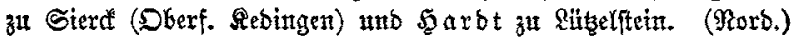

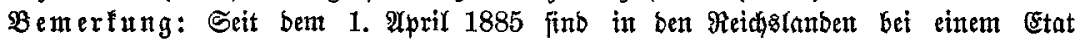

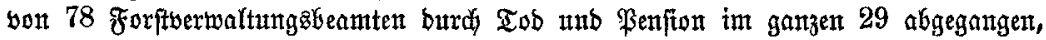

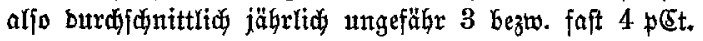

